\title{
28 Research Square \\ GC-MS analysis of important bioactive compounds in bulbs and callus of in vitro produced Urginea maritima.
}

Hany El-Naggar ( $\square$ hanyelnaggar@hotmail.com )

Alexandria University Faculty of Agriculture

Ashraf M. Shahata

Alexandria University Faculty of Agriculture

Mennat-allah Morsi

Alexandria University Faculty of Agriculture

\section{Research Article}

Keywords: Urginea maritima, in vitro, callus, GC-MS, bioactive compounds, antioxidants.

Posted Date: March 7th, 2022

DOI: https://doi.org/10.21203/rs.3.rs-1382918/v1

License: (1) (i) This work is licensed under a Creative Commons Attribution 4.0 International License.

Read Full License 


\section{Abstract}

Medicinal herbs are the main source of bioactive compounds used in the medicine industry. Urginea maritima is an important medicinal and ornamental plant cultivated in the Mediterranean region. This study reports an efficient protocol for in vitro propagation of Urginea and investigates the most important bioactive compounds present in the bulbs and in vitro-produced callus.

The least number of days for callus induction and shoot regeneration was achieved in Murashige and Skoog MS basal media supplemented with (1 mg/L 1-naphthaleneacetic acid NAA + $0.1 \mathrm{mg} / \mathrm{L} 6$ benzylaminopurine, BAP) and ( $1 \mathrm{mg} / \mathrm{L} \mathrm{NAA}+0.4 \mathrm{mg} / \mathrm{L} \mathrm{BAP})$, respectively, while the highest number of shoots and fresh weight were obtained in media supplemented with $1 \mathrm{mg} / \mathrm{L} \mathrm{NAA}+0.5 \mathrm{mg} / \mathrm{L}$ BAP.

Gas chromatography-mass spectrometry GC-MS analysis of Urgenia bulbs methanol extract showed the existence of important bioactive compounds such as palmitic acid $\left(\mathrm{C}_{16} \mathrm{H}_{32} \mathrm{O}_{2}\right)$, 9-hexadecenoic acid $\left(\mathrm{C}_{16} \mathrm{H}_{30} \mathrm{O}_{2}\right)$, phthalic acid 2-ethylhexyl propyl ester $\left(\mathrm{C}_{19} \mathrm{H}_{28} \mathrm{O}_{4}\right)$, tetradecanoic acid $\left(\mathrm{C}_{14} \mathrm{H}_{28} \mathrm{O}_{2}\right)$, undecanoic acid $\left(\mathrm{C}_{11} \mathrm{H}_{22} \mathrm{O}_{2}\right)$, and oleic acid $\left(\mathrm{C}_{18} \mathrm{H}_{34} \mathrm{O}_{2}\right)$, in addition to other important compounds such as 13heptadecyn-1-ol, 9,12- octadecadienoic acid, 1-monolinoleoylglycerol trimethylsilyl ether, 2-methyl-1hexadecanol and octadecanoic acid. These compounds possess antioxidant, anti-inflammatory, anti-HIV, antifungal, antiasthma, and antimicrobial properties. Callus methanol extracts showed a reduction in the percentages of most phyto-components compared to bulb extract except for oleic acid, 3-(octadecyloxy) propyl ester and 3-hydroxydodecanoic acid; on the other hand, some compounds were detected only in callus extract possessing anticancer and anti-inflammatory effects, such as farnesol $\left(\mathrm{C}_{15} \mathrm{H}_{26} \mathrm{O}\right)$, 7-methylZ-tetradecen-1-ol acetate $\left(\mathrm{C}_{17} \mathrm{H}_{32} \mathrm{O}_{2}\right)$, ethyl iso-allocholate $\left(\mathrm{C}_{26} \mathrm{H}_{44} \mathrm{O}_{5}\right)$, 4-trifluoroacetoxypentadecane $\left(\mathrm{C}_{17} \mathrm{H}_{31} \mathrm{~F}_{3} \mathrm{O}_{2}\right)$ and 2-hydroxyhexadecanoic acid $\left(\mathrm{C}_{16} \mathrm{H}_{32} \mathrm{O}_{3}\right)$.

\section{Key Message}

This research aimed to produce adequate amounts of secondary metabolites from Urginea. Combining NAA and BAP was effective in callus induction and bioactive compound production. GC-MS detected important bioactive compounds.

\section{Introduction}

Medicinal plants are considered the main reservoir for useful and new chemical compounds that can be used in modern drug formulation. White squill (Urginea maritima), belonging to the family Liliaceae, is a medicinal and ornamental plant abundant in the Mediterranean area and North Africa in sandy soils and hills. It is a winter perennial onion-like bulbous plant with large dark green leaves, that grows from autumn to spring and produces flowers after the growth of leaves. The flowers are found in dense clusters. After spring, the bulbs enter a dormant stage during the summer (Aasim et al. 2014; Ben Hamouda et al. 2016). The plant is used as a folk medicine in different countries and is a source of many bioactive compounds present in its bulbs (Reddy et al. 2013). 
Urginea closely resembles Digitalis as it diminishes the force and frequency of the heart's action (Kopp et al., 1996). From the phytochemical point of view, U. maritima contains 1-3\% cardiac glycosides, anthocyanins, fatty acids, flavonoids, polysaccharides and calcium, thus justifying their tonic action and diuretic actions (lizuca et al. 2001). Prabakaran et al. (2016) reported that Urginea bulbs are used against arthritis and for the removal of free carcinogenic radicals through the existence of antioxidants.

Plant tissue culture has become a powerful technique for the propagation and production of secondary metabolites and protecting threatened and wild growing species (Reddy et al. 2013). Callogenesis is a new and continuous method for secondary metabolite production (Isah et al. 2018).

Using bulb scales as a traditional method for Urginea propagation is very slow and time consuming therefore, using tissue culture as an alternative method for propagation has become essential, and research on the micropropagation of Urginea species is limited (Aasim et al. 2014).

Gas chromatography-mass spectrometry (GC-MS) is an analytical method that combines the features of gas chromatography and mass spectrometry to identify different substances within a tested sample (Alam et al. 2014).

GC-MS is a powerful technique used for the identification and quantification of bioactive compounds in plant extracts. GC-MS has been applied for the analysis of different medicinal herbs and proven to be a valuable method for detecting different hydrocarbons, volatile oils, acids, esters, alkaloids, fatty acids, and amino and nitro compounds (Parthipan et al. 2015; Srivastava et al. 2015).

Analysis of Urginea bulbs using GC-MS showed the existence of various secondary metabolites, such as organic acids, phenolic compounds, phytosterols, esters and ketones (Prabakaran et al. 2016).

The present study was undertaken to establish an efficient micropropagation and callus induction protocol for Urginea maritima and to detect the most important bioactive compounds in the bulb and in in vitro produced callus extract through GC-MS analysis.

\section{Materials And Methods}

The present study was conducted at the Tissue Culture and Biotechnology Lab. Department of Floriculture, Faculty of Agriculture, Alexandria University, Egypt during the period of 2016-2020.

\section{Source of plant material}

Urginea maritima bulbs were collected at a depth of 50 to $70 \mathrm{~cm}$ under the soil surface from coordinates $30^{\circ} 55^{\prime} 25.4^{\prime \prime} \mathrm{N}, 29^{\circ} 15^{\prime} 6.84^{\prime \prime}$ E North coast, Matrouh governorate Egypt in December and January $2016 / 2017$ and repeated the next year at the same time. All collected bulbs were homogenous in size with an average weight $(100 \mathrm{~g})$ and average dimensions ( $11.4 \mathrm{~cm}$ height and $9.3 \mathrm{~cm}$ diameter) and maintained in the nursery of the Floriculture Department, Faculty of Agriculture, Alexandria University, Egypt where they were used later as the source of the explants. 


\section{Source and sterilization of explants}

Disc plates were excised from Urginea maritima bulbs and used as explants, and the average number of bulb leaves per bulb ranged from 25-35 scaly leaves. The bulbs were first washed thoroughly under running tap water for 15 minutes to remove any foreign materials (dirt, soil and dry scales). The excised explants were washed using home detergent for 30 minutes, followed by washing with fungicide Benlate $5 \%$ with 2 drops of the wetting agent "Tween 20" (Sigma-Aldrich, Saint-Louis, Missouri USA) for 30 minutes, then surface sterilized by immersing in $70 \%$ ethyl alcohol for 5 minutes followed by $0.1 \%$ mercuric chloride (Chemajet Chemical Co., Egypt) with 2 drops "Tween 20" for 15 minutes, and finally rinsed three times with sterilized distilled water to remove any residues of ethanol or mercuric chloride.

\section{Micropropagation stages}

\section{Initiation stage (callus induction):}

Disc plates of approximately $1 \mathrm{~cm}^{2}$ of Urginea maritima were inoculated individually into solidified MS medium (Murashige and Skoog medium 1962) (4.43 g/L) supplemented with sucrose (30 gm/L), phytagel $(2 \mathrm{gm} / \mathrm{L})$ and a combination of two plant growth regulators: 6-benzylaminopurine (BAP) at concentrations of $0.0,0.1,0.2$ and $0.3 \mathrm{mg} / \mathrm{l}$ and nephthalineacetic acid (NAA) at 0.0, 1.0, 2.0 and 3.0 $\mathrm{mg} / \mathrm{L}$. The $\mathrm{pH}$ of the media was adjusted to $5.8 \pm 0.1$ using a pH meter ( 211 Hanna Instruments Romania), and then the media were autoclaved at $121 \pm 1^{\circ} \mathrm{C}$ for $20 \mathrm{~min}$ under a pressure of $1.5 \mathrm{bar} / \mathrm{cm}^{2}$ (Daihan Labtech Co.- LTD - model LAC-5082SE - Korea). Explants were inoculated on MS medium, with a single explant per jar with dimensions of $9 \mathrm{~cm}$ height and $5 \mathrm{~cm}$ diameter. All jars were capped and sealed with parafilm (Laboratory zfilm Pechiney plastic Packaging, Chicago, IL 60631) and incubated in the growth room.

\section{Multiplication stage}

The calli from the initiation stage were sectioned into pieces of approximately $0.5 \mathrm{~cm}$ and recultured on MS basal medium at $4.43 \mathrm{gm} / \mathrm{L}$, sucrose at $30 \mathrm{gm} / \mathrm{L}$, phytagel at $2 \mathrm{gm} / \mathrm{L}$ and supplemented with BAP at $0.0,0.3,0.4$, and $0.5 \mathrm{mg} / \mathrm{L}$ and NAA at $0.0,1.0,2.0$, and $3.0 \mathrm{mg} / \mathrm{L}$. The $\mathrm{pH}$ was adjusted to $5.8 \pm 0.1$ by autoclaving at $121 \pm 1{ }^{\circ} \mathrm{C}$ for $20 \mathrm{~min}$.

\section{Culture environmental conditions}

Cultured jars were incubated in the growth room at $25 \pm 1{ }^{\circ} \mathrm{C}$, illuminated with fluorescent lamps located $40 \mathrm{~cm}$ above the culture jars, giving an average irradiance of $55-56 \mu \mathrm{mole} / \mathrm{m}^{2} / \mathrm{S}$ depending on the age of the lamp, for $16 / 8 \mathrm{hr}$. light/dark photoperiod respectively, and the relative humidity was $80 \%$.

\section{Bioactive compound extraction from bulbs and callus}

The Hemalata and Kameshwari (2015)method was used with a modification, and fresh squill bulbs were cleaned thoroughly to remove any soil or debris. The bulbs were dried in an oven at $70{ }^{\circ} \mathrm{C}$ for 
approximately 72 hours. The dried plant material was ground to a fine powder, and $30 \mathrm{~g}$ of the powder was suspended in $100 \mathrm{ml}$ methanol. The obtained solution was incubated at $50-60{ }^{\circ} \mathrm{C}$ for 1 hour and concentrated by evaporating methanol. The obtained calli were used for the extraction and quantification of bioactive compounds by the same method. The modification was performed using centrifugation at $3000 \mathrm{rpm}$ for $5 \mathrm{~min}$. to purify the extract.

\section{GC-MS analysis}

A diluted volume of $1.00 \mu \mathrm{l}$ was injected into the system using an Al-3000 autoinjector with split injection mode (1:30); the injector temperature was $250^{\circ} \mathrm{C}$. The test was run using an Ultratrace G. C ISQMS Thermo Fisher Germany with a TG5sil/ms capillary column of $30 \mathrm{~m}$ length. Helium gas was used as the carrier gas with a total flow of $1.5 \mathrm{~mL}$ (column flow of $1.5 \mathrm{~mL} / \mathrm{min}$.). The oven temperature was programmed from $40^{\circ} \mathrm{C}\left(1 \mathrm{~min}\right.$ hold time) to $180^{\circ} \mathrm{C}\left(1 \mathrm{~min}\right.$ hold time) and to $200{ }^{\circ} \mathrm{C}$ ( 2 min hold time). The total running time was $50 \mathrm{~min}$. For the ISQ mass spectrometric test, through a transfer line $\left(250^{\circ} \mathrm{C}\right)$, the ion-source temperature was $230^{\circ} \mathrm{C}$; the solvent cut time was $2.00 \mathrm{~min}$; and the detector gain was 0.70 $\mathrm{kV}$. Compounds were identified by their mass spectra and retention indices using the NIST Mass Spectral Library and the Retention Index Database. The GC-MS Insight xcalibur software package was used to process the data (Shwaish and Al-Imarah 2017).

\section{Total phenolic content}

The total phenolic content of the methanolic extract of Urginea bulbs was determined according to the Folin-Ciocalteu method. The methanol solution of each sample $(0.2 \mathrm{~mL}, 100 \mu \mathrm{g} / \mathrm{mL})$ was mixed with Folin-Ciocalteu reagent ( $2 \mathrm{~mL}, 1: 10$ diluted with distilled water). After $5 \mathrm{~min}$, saturated $\mathrm{NaHCO}_{3}$ solution $(1.5 \mathrm{~mL}, 60 \mathrm{~g} / \mathrm{L}$ distilled water) was added. All mixtures were allowed to stand for $90 \mathrm{~min}$ at room temperature, and then absorption of the solutions was measured at $725 \mathrm{~nm}$ using a spectrophotometer. The same procedures were repeated for the callus samples (Tofighi et al. 2016).

\section{Statistical analysis}

All the experiments carried out during this study were designed as factorial experiments; the main factor was NAA, and the subfactor was BAP. The experimental layout was a completely randomized design (CRD) according to (Gomez and Gomez, 1984). The recorded data were analyzed statistically by using analysis of variance (ANOVA) with SAS software (copyright 2002 by SAS Institute Inc., Cary, NC, USA), and the averages were compared by the least significant difference (L.S.D) (Steel et al. 2006), and the significance level was determined at $p \leq 0.05$.

\section{Results}

\section{Initiation stage}


As shown in Table 1, it appeared that the number of days for callus induction was inversely proportional to NAA concentration, and the lowest number of days for callus induction (87 days) was obtained at 1 $\mathrm{mg} / \mathrm{L}$ NAA + $0.1 \mathrm{mg} / \mathrm{L}$ BAP (Fig 1a).

The callus fresh weight increased significantly with increasing NAA concentration, reaching the highest value $(2.24 \mathrm{~g})$ at $2 \mathrm{mg} / \mathrm{L} \mathrm{NAA}+0.1 \mathrm{mg} / \mathrm{L}$ BAP. NAA at its highest concentration ( $3 \mathrm{mg} / \mathrm{L})$ caused a reduction in fresh weight and delayed callus induction. The greatest total phenolic content was obtained at the lowest concentrations of NAA and BAP (1.0 and $0.1 \mathrm{mg} / \mathrm{L}$, respectively), and increasing NAA or BAP caused a significant reduction in phenolic content in callus.

The fastest callus with the highest phenolic content produced at $1 \mathrm{mg} / \mathrm{L} \mathrm{NAA}+0.1 \mathrm{mg} / \mathrm{L}$ BAP from the callogenesis stage, was used as an explant for the multiplication stage. As shown in Table 2, $1 \mathrm{mg} / \mathrm{L} \mathrm{NAA}$ $+0.4 \mathrm{mg} / \mathrm{L} \mathrm{BAP}$ yielded the lowest number of days for shoot formation (42.5 days), while the highest number of shoots was obtained at $1 \mathrm{mg} / \mathrm{L} N A A+0.5 \mathrm{mg} / \mathrm{L}$ BAP, reaching 5.5 shoots with the highest fresh weight (Fig. 1c and $1 \mathrm{~d}$ ). The shoot height increased significantly with increasing NAA concentration and then declined at the highest BAP concentration. The total phenolics increased with increasing NAA and BAP concentrations, reaching a peak at $2 \mathrm{mg} / \mathrm{L} \mathrm{NAA}+0.5 \mathrm{mg} / \mathrm{L}$ BAP.

\section{GC-MS analysis of bulbs and calli methanol extract}

Tables 3 and 4 show the GC-MS analysis of Urginea maritima bulbs and calli methanolic extracts, indicating a list of 29 and 25 different bioactive compounds, respectively, which are used pharmaceutically as antibacterial, antimicrobial, anti-inflammatory, antiasthma, diuretic, antioxidant, prevention of certain cancers, heart protection, antimalaria, dermatologic agent against achne, hypocholesterolemia, prevention and treatment of diabetic retinopathy (Parthipan et al. 2015; Prabakaran et al. 2016; Ambrin et al. 2019).

Among the bioactive compounds detected in Urginea bulbs extract were n-hexadecanoic or palmitic acid $\left(\mathrm{C}_{16} \mathrm{H}_{32} \mathrm{O}_{2}\right)$ with the highest peak area $11.53 \%$ and retention time 25.06 minutes followed by 9hexadecenoic acid or palmitoleic acid $\left(\mathrm{C}_{16} \mathrm{H}_{30} \mathrm{O}_{2}\right) 6.26 \%$, phthalic acid 2-ethylhexyl propyl ester $\left(\mathrm{C}_{19} \mathrm{H}_{28} \mathrm{O}_{4}\right) 5.40 \%$, tetradecanoic acid $\left(\mathrm{C}_{14} \mathrm{H}_{28} \mathrm{O}_{2}\right) 4.61 \%$, 1,2- benzendicarboxylic acid, diisooctyl ester $\left(\mathrm{C}_{24} \mathrm{H}_{38} \mathrm{O}_{4}\right) 3.69 \%$, undecanoic acid $\left(\mathrm{C}_{11} \mathrm{H}_{22} \mathrm{O}_{2}\right) 3.20 \%$ and oleic acid $\left(\mathrm{C}_{18} \mathrm{H}_{34} \mathrm{O}_{2}\right) 3.16 \%$ in addition to other important compounds such as 13-heptadecyn-1-ol 2.70\%, 9,12-octadecadienoic acid 2.51\%, 1monolinoleoylglycerol trimethylsilyl ether $2.46 \%$, 2-methyl-1-hexadecanol 1.99\%, deacetylvindoline 1.86\%, octadecanoic acid $1.53 \%$, 3-(octadecyloxy) propyl ester $1.00 \%$ and ajmalicine $0.4 \%$ along with different compounds identified by GC-MS (Table 3). On the other hand, the phyto-components identified in callus methanol extracts showed a reduction in the percentages of most active ingredients compared to bulb extracts, except for oleic acid, 3-(octadecyloxy) propyl ester, 3-(octadecyloxy) propyl ester and 3hydroxydodecanoic acid as their concentrations were higher in the callus extracts. Additionally, some compounds were detected only in callus extracts such as farnesol $5.87 \%$, 7-methyl-Z-tetradecen-1-ol 
acetate $1.70 \%$, ethyl iso-allocholate $1.15 \%$, 4-trifluoroacetoxypentadecane $0.46 \%$ and 2 hydroxyhexadecanoic acid $0.31 \%$ (Fig. 2 and 3 ).

\section{Discussion}

It was observed that (1.0 mg/L NAA $+0.1 \mathrm{mg} / \mathrm{L} \mathrm{BAP})$ accelerated callus induction (87 days) while increasing NAA concentration ( $3 \mathrm{mg} / \mathrm{L}$ ) caused a delay in callus induction (125.5 days) (Table 1 ). Verma et al. (2011) reported previously that auxins have a very important role in callus formation and suppression in calli induction occurred at high auxin concentrations. The maximum callus fresh weight was obtained with $2 \mathrm{mg} / \mathrm{L}$ NAA $+0.1 \mathrm{mg} / \mathrm{L}$ BAP $(2.24 \mathrm{~g})$ (Table 1).

Aasim et al. 2014 reported that $U$. maritima explants were intractable and needed 3 subcultures to attain the desired regeneration taking 168 days. In our work, we archived the regenerated shoots after approximately 130 days through the production of callus first and then used the fastest formed callus as an explant for the multiplication stage.

Increasing the concentration of BAP with or without NAA promoted shoot number and height, except for the highest BAP concentration $(0.5 \mathrm{mg} / \mathrm{L})$, as it suppressed shoot height. The highest number of shoots was obtained at $1 \mathrm{mg} / \mathrm{L} \mathrm{NAA}+0.5 \mathrm{mg} / \mathrm{L}$ BAP (5.5 shoots) (Table 2). Similar results were obtained by Aasim et al. 2014, who recorded that the highest frequency of Urginea axillary bulblet regeneration of $91.67 \%$ with a mean number of 3.57 axillary bulblets per explant was recorded on MS basal medium containing $0.55 \mathrm{mg} / \mathrm{L}$ thidiazuran (TDZ), while the highest TDZ concentration $(0.65 \mathrm{mg} / \mathrm{L})$ caused a reduction in the number and diameter of regenerated bulblets. Similarly, Han et al. 2004; Nakano et al. 2000 mentioned that cytokinins at high concentrations generally reduce and inhibit shoot formation from Lilium bulb scales.

Increasing NAA concentration caused a delay in days for shoot proliferation, while NAA at $1 \mathrm{mg} / \mathrm{L}+0.4$ $\mathrm{mg} / \mathrm{L}$ BAP accelerated shoot formation (42.5 days) (Table 2, Fig. 1c).

The greatest total phenolic content accumulation was detected in callus and regenerated shoots at 1 $\mathrm{mg} / \mathrm{L} \mathrm{NAA}+0.1 \mathrm{mg} / \mathrm{L}$ BAP and $2 \mathrm{mg} / \mathrm{L} \mathrm{NAA}+0.5 \mathrm{mg} / \mathrm{L}$ BAP, respectively (Tables 1 and 2). Taiz and Zeiger (2002) mentioned that phenylalanine and phenylalanine ammonia-lyase (PAL) play a great role in the biosynthesis of both phenolic compounds and natural auxins such as indole acetic acid (IAA) through the shikimic pathway, while synthetic auxins such as NAA have a similar effect as IAA, and applying NAA to the media affected the PAL enzyme, which is the precursor of phenolic compounds leading to an increase in total phenol production. Reddy et al. (2013) indicated that combining NAA and BAP is effective in callus induction and enhancing bioactive compound production.

GC-MS analysis for Urginea bulbs and callus methanol extract showed the existence of 29 and 25 important bioactive products, respectively, including alkaloids, terpenes, fatty acids and antioxidants possessing many pharmaceutical, medicinal and antimicrobial properties. 
Among the bioactive compounds found in both bulbs and callus methanol extract $n$-hexadecanoic $\left(\mathrm{C}_{16} \mathrm{H}_{32} \mathrm{O}_{2}\right)$, octadecanoic acid $\left(\mathrm{C}_{18} \mathrm{H}_{36} \mathrm{O}_{2}\right)$, 9-hexadecenoic acid or palmitoleic acid $\left(\mathrm{C}_{16} \mathrm{H}_{30} \mathrm{O}_{2}\right)$ and 9,12octadecadienoic acid linoleic acid ester $\left(\mathrm{C}_{18} \mathrm{H}_{32} \mathrm{O}_{2}\right)$ were found to have anticancer, antioxidant, antiinflammatory, nematicide, antihistaminic and antiarthritic activities. (Parthipan et al. 2015; Prabakaran et al. 2016). Similar reported compounds were made in Croton tiglium seeds and found to have potential insecticide, hypocholesterolemic, hepatoprotective, antiacne, and antieczemic effects (Prabakaran et al. 2016). The methyl esters and phenolic acids in the Urginea extract have been reported to possess antioxidant and anti-inflammatory properties due to their redox activities, inhibiting and scavenging lipid peroxidation (Dhivya and Kalaichelvi 2017). Ajmalicine possesses antihypertensive and antimicrobial activities and is also used in treating circulatory diseases and high blood pressure (Ambrin et al. 2019), while Ajmaline is an anti-arrhythmic compound used in the treatment of acute atrial or ventricular tachycardia (Boga et al. 2019).

The phyto-components identified in callus methanol extracts showed a reduction in the percentages of active ingredients compared to bulb extract except for oleic acid, 3-(octadecyloxy) propyl ester and 3hydroxydodecanoic acid, which possess antifungal effects for plant and human fungal pathogens (Abubacker et al. 2014). Additionally, some important compounds were detected in callus extraction only, such as farnesol $5.87 \%$, which is a sesquiterpene alcohol possessing anticancer and anti-inflammatory effects and can modulate various tumorigenic proteins by downregulating the expression of interleukin- 6 in humans (Jung et al. 2018), oxirane hexadecyl 5.22\% and 7-methyl-Z-tetradecen-1-ol acetate 1.70\%, which act as anticancer, anti-inflammatory and hepatoprotective agents. Similar results were obtained by Reddy et al. (2013), who mentioned that in vitro callus culture of Urginea enhanced the formation of many important secondary metabolites.

\section{Conclusion}

For in vitro production of Urginea maritima, MS medium amended with $1 \mathrm{mg} / \mathrm{L} N A A+0.1 \mathrm{mg} / \mathrm{L}$ BAP gave the least number of days for callus induction (87 days), while $1 \mathrm{mg} / \mathrm{L} \mathrm{NAA}+0.4 \mathrm{mg} / \mathrm{L}$ BAP gave the least number of days for shoot formation (42.5 days), and the highest number of shoots was obtained at 1 $\mathrm{mg} / \mathrm{L} \mathrm{NAA}+0.5 \mathrm{mg} / \mathrm{L}$ BAP, reaching 5.5 shoots with the highest fresh weight.

Phyto-components identified using GC-MS analysis showed great potential for Urginea as an important medicinal plant due to the presence of bioactive medicinal compounds. In the present study, twenty-nine and twenty-five bioactive compounds were identified in methanol extracts of Urginea bulbs and callus cultures, respectively. Urginea derived bioactive compounds are used as sources of antibiotics, antioxidants, anti-inflammatory agents, and anticancer compounds and possess pharmaceutical activities used for drug formulation. The pharmacological activity of these compounds should be evaluated. Further phytochemical and pharmacological investigation of bulbs and callus cultures of $U$. maritima is needed for the development of new drugs.

\section{Declarations}




\section{Acknowledgement}

The authors express their deep gratitude to the Department of Floriculture, Faculty of Agriculture, Alexandria University, Egypt, for providing the infrastructure, laboratories, chemicals, nurseries and all the facilities to help accomplish this research.

\section{Author contributions}

The research idea, experimental design and statistical analysis were made by [Hany M. El-Naggar] the main author and primary investigator. Plant materials and data, tissue culture and lab work were made by master's student [Mennat-Allah Ali Morsi], while the writing and revising of the manuscript were done by [Ashraf M. Shahata]. This research is a part of master's thesis. All the authors read the manuscript and approved its final form.

\section{Funding}

This research is a self-funding research.

Conflict of interest All the authors declare that they have no conflicts of interest.

\section{Ethical statement}

All the authors declare and certify that all the work done in this research is the author's original work and has not been submitted to any other journal for publication, and the paper is not considered for publication elsewhere. All the data in this paper are original and reflect the active contribution of the author and coauthors leading to the manuscript.

\section{References}

1. Aasim M, Khawar KM, Özcan S (2014) In Vitro Regeneration of Red Squill Urginea Maritima (L.) Baker Using Thidiazuron. Biotechnology and Biotechnological Equipment, 22(4), 925-928.

2. Abubacker MN, Devi PK (2014) In vitro antifungal potentials of bioactive compound oleic acid, 3(octadecyloxy) propyl ester isolated from Lepidagathis cristata Wild. (Acanthaceae) inflorescence. Asian Pacific Journal of Tropical Medicine. 7(1):190-193.

3. Al-Garawi NI, Nidaa AA, Khansaa AS, Zina KA (2019) Analysis of bioactive phytochemical compound of (Cyperus alternifolius L.) By using gas chromatography-mass spectrometry IOP Conf. Ser. Mater. Sci. Eng. 571012047.

4. Al-Marzoqi AH, Imad HH, Salah Al (2015) Analysis of bioactive chemical components of two medicinal plants (Coriandrum sativum and Melia azedarach) leaves using gas chromatographymass spectrometry (GC-MS). African journal of biotechnology. 14(40), pp. 2812-2830.

5. Ambrin G, Mohammad A, Abdulaziz AA, Abeer H, Elsayed FA, Altaf A (2019) Conversion of Cytochrome P450 2D6 of human into a FRET-based tool for real-time monitoring of ajmalicine in 
Living cells. Front. Bioeng. Biotechnol. Vol 7: 3-5.

6. Astudillo M, Alma C, Meana CG, Patricia L, Maria A, balboa JB (2018) Occurrence and biological activity of palmitoleic acid isomers in phagocyte cells. Journal of lipid research volume 59 no 2 p: 237-249.

7. Ben Hamouda A, Chaieb I, Zouari L, Zarrad K, Laarif A (2016) Toxicological effects of Urginea maritima (L.) against the red flour beetle (Coleoptera: Tenebrionidae). Journal of Entomology and Zoology Studies. 4(1): 17-20.

8. Boga M, Murat B, Esra EÖ, Hasan Ş (2019) Chemical and biological perspectives of monoterpene indole alkaloids from Rauwolfia species. Studies in Natural Products Chemistry Vol. 61, P: 251-299.

9. Dhivya SM, Kalaichelv, K (2017) Phytochemical studies and gas chromatography mass-spectrometry analysis of Sarcostemma breve stigma. Asian J Pharm Clin Res, Vol 10, Issue 3, 462-466.

10. Gomez k, Gomez AA (1984) Statistical procedures for agriculture research. An international rice research institute book. A Wiley-intersci. Publisher, New York. 7-240.

11. Hameed IH, Hussein JH, Muhanned AK, Nidaa SH (2015) Identification of five newly described bioactive chemical compounds in methanolic extract of Mentha viridis by using gas chromatography - mass spectrometry (GC-MS). J. Pharmacognosy Phytother Vol. 7(7), pp.107-125.

12. Han BH, Hee JY, Byeoung WY, Kee YP (2004) In vitro micropropagation of Lilium longiflorum 'Georgia' by shoot formation as influenced by addition of liquid medium. Scientia Horticulturae. 103:39-49.

13. Hemalata SK, Kameshwari MN (2015) Anti-Inflammatory Activity in Urginea wightii, (Lakxmin) Kunth, Hyacinthaceae. International journal of pure \& applied bioscience. 3(3): 249-253.

14. lizuca $M$, Warashina $T$, Noro $T$ (2001) Bufadienolides and a new lignan from the bulbs of Urginea maritima. Chem. Pharm. Bull. 49(3):282-286.

15. Isah T, Umar S, Mujib A, Sharma MP (2018) Secondary metabolism of pharmaceuticals in the plant in vitro cultures, strategies, approaches and limitations to achieving higher yield. Plant Cell Tissue Organ Cult 132:239-265.

16. Jung YY, Sun TH, Gautam S, Lu F, Frank A, Kwang SA (2018) Potential anti-inflammatory and anticancer properties of farnesol. Molecules. Oct 31: 23(11):2827.

17. Karthi S, Beena S, Abdul Jaffar AH (2015) Efficacy of methanolic extract of a marine ascidian, Lissoclinum bistratum for antimicrobial activity. JCBPS; Section B; Vol. 5, No. 4; 4119-4125.

18. Kopp B, Krenn L, Draxler M, Hoyer A, Terkola R, Vallaster P, Robien W (1996) Bufadienolides from Urginea maritima from Egypt. Phytochemistry, 42(2):513-522.

19. Murashige T, Skoog F (1962) A revised medium for rapid growth and bioassays with tobacco tissue culture. Physiol Plant 15:473-497.

20. Nakano M, Toshiaki S, Sakae S, Hiroyuki S (2000) Decrease in the regeneration potential of long-term cell suspension cultures of Lilium formosanum Wallace and its restoration by the auxin transport inhibitor, 2,3,5 triiodobenzoic acid. Plant Science 158: 129-137. 
21. Parthipan B, Suky MGT, Mohan VR (2015) GC-MS Analysis of Phytocomponents in Pleiospermium alatum (Wall. ex Wight \& Arn.) Swingle, (Rutaceae). J. of Pharmacognosy and Phytochem.; 4(1): 216222.

22. Prabakaran R, Joseph B, Pradeep N (2016) Phyto medicinal compounds from Urginea indica Kunth: A synthetic drugs potential alternative. British Journal of Pharmaceutical Research (BJPR) 11(5): 1-9.

23. Reddy AS, Sita PD, Ravi SK (2013) In vitro cell culture of Charybdis congesta for enhanced production of secondary metabolites: Proscillaridin A, Scillaren A and Scilliroside. African Journal of Biotechnology, 12(15): 1754 - 1759.

24. Shwaish T, Al-Imarah FJM (2017) Chemical composition of Cordia myxa fruit: Phytochemical screening and identification of some bioactive. Int. J. Adv. Res. 5(9), 1255-1260.

25. Srivastava R, Alok M, Amita V (2015) GC-MS Analysis of phytocomponents in, pet ether fraction of Wrightia tinctoria seed. Phcog J | Jul-Aug Vol: 7 Issue 4.

26. Steel RGD, Torrie JH, Dicky DA (2006) Principles and procedures of statistics- a biometric approach. Third edition. [S.I.]: Academic internet Publishers.

27. Taiz L, Zeiger E (2002) Plant Physiology. 3rd. Sunderland, Mass: Sinauer Associates Inc., U.S.A., 690 p.

28. Tofighi Z, Ghazi SN, Hadjiakhoondi A, Yassa N (2016) Determination of cardiac glycosides and total phenols in different generations of Securigera securidaca suspension culture. Research Journal of Pharmacognosy (RJP) 3(2): 25-31.

29. Verma D, Joshi R, Shukla A, Kumar P (2011) Protocol for in vitro somatic embryogenesis and regeneration of rice (Oryza sativa L.). Indian J. Exp. Biol., 49, 958-963.

\section{Figures}




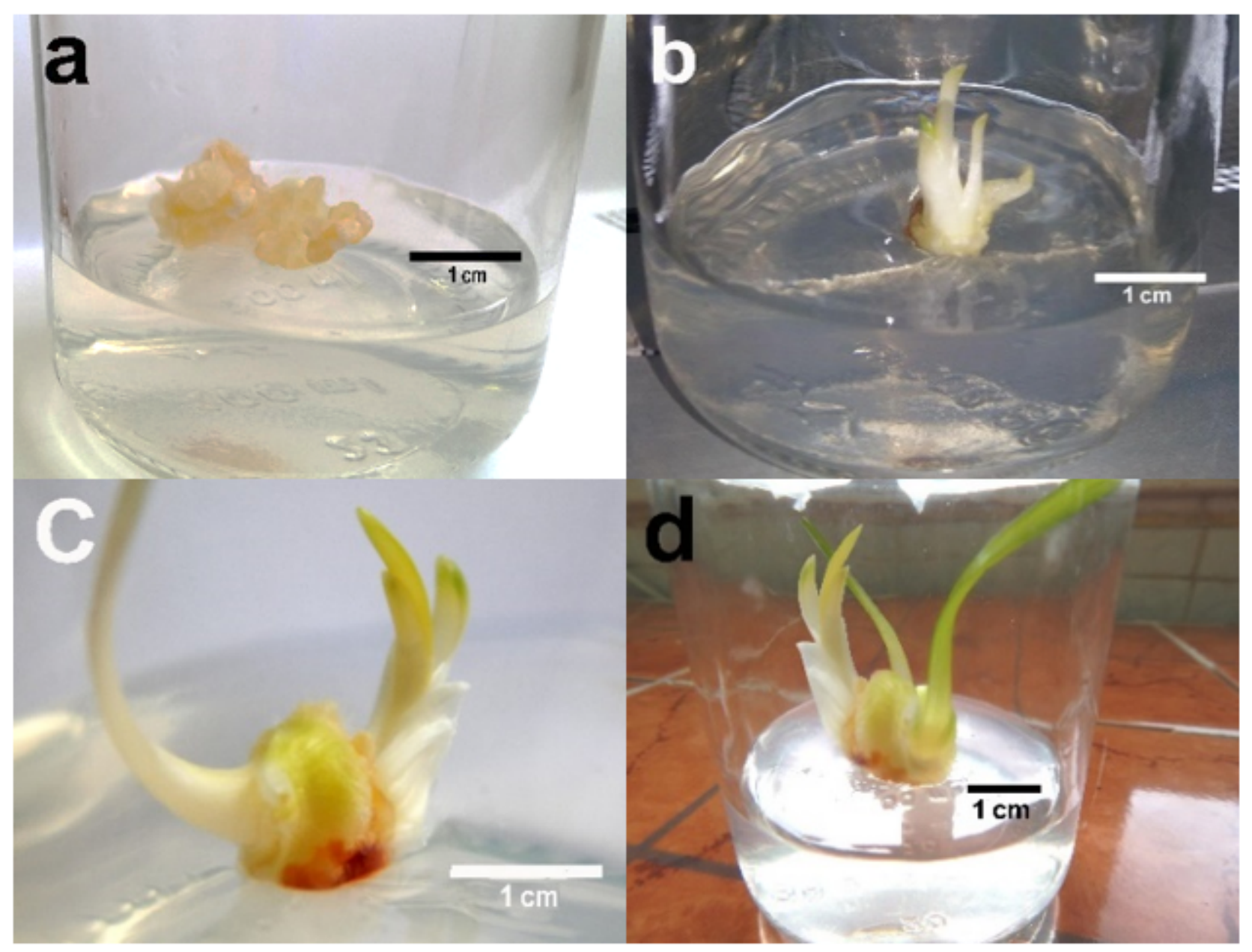

\section{Figure 1}

a. Callus induced from disc plates in MS media containing $1 \mathrm{mg} / \mathrm{L} \mathrm{NAA}+0.1 \mathrm{mg} / \mathrm{L}$ BAP.

b. Beginning of shoot development in MS media aged 4 weeks.

c. Shoots regenerated and developed in MS amended with $1 \mathrm{mg} / \mathrm{L} \mathrm{NAA}+0.4 \mathrm{mg} / \mathrm{L}$ BAP aged 6 Weeks.

d. Shoots regenerated and developed in MS amended with $1 \mathrm{mg} / \mathrm{L} \mathrm{NAA}+0.5 \mathrm{mg} / \mathrm{L}$ BAP aged 6 Weeks. 


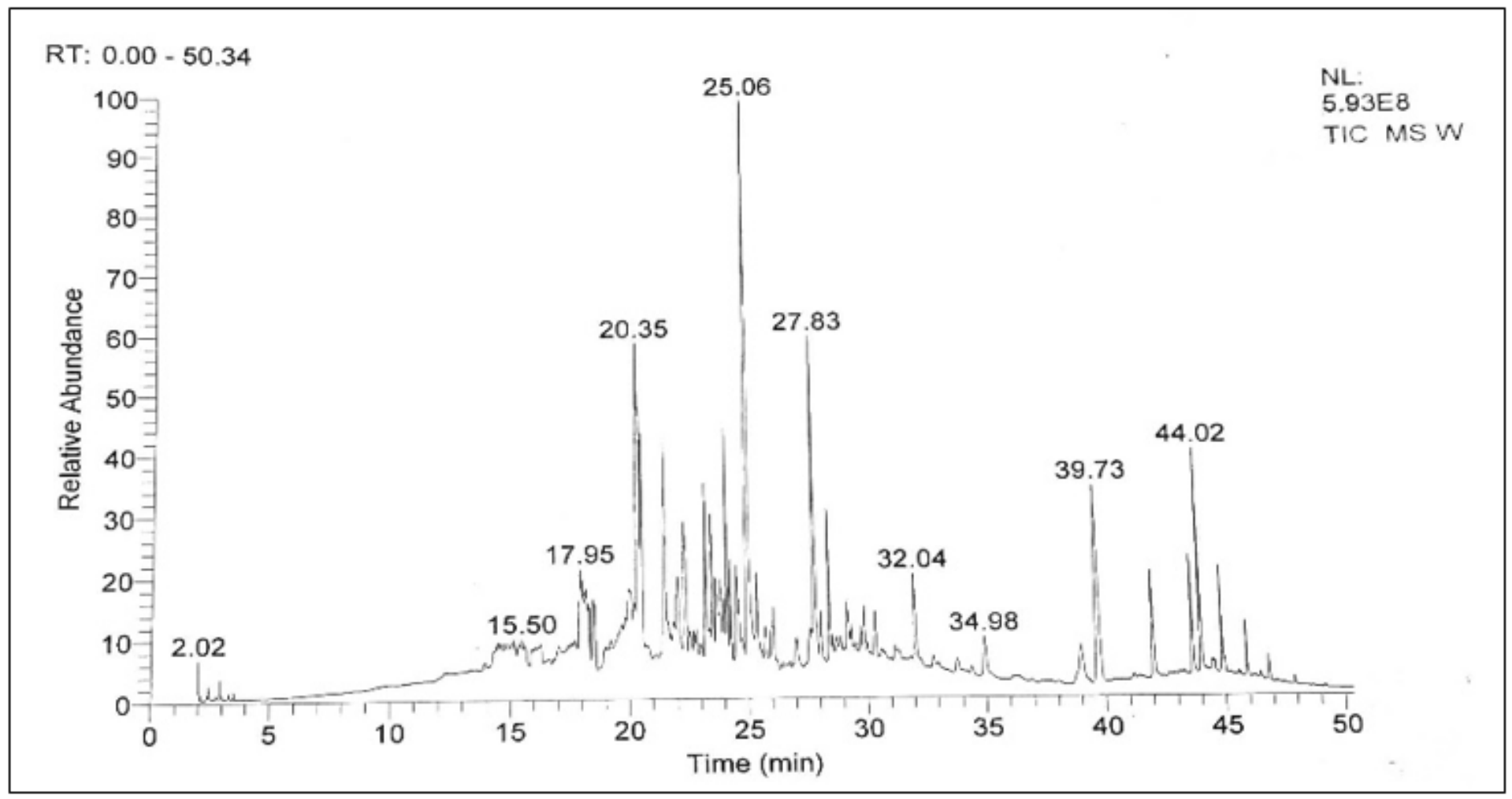

Figure 2

Gas chromatography-mass spectrometry chromatogram of $U$. maritima bulbs methanolic extract.

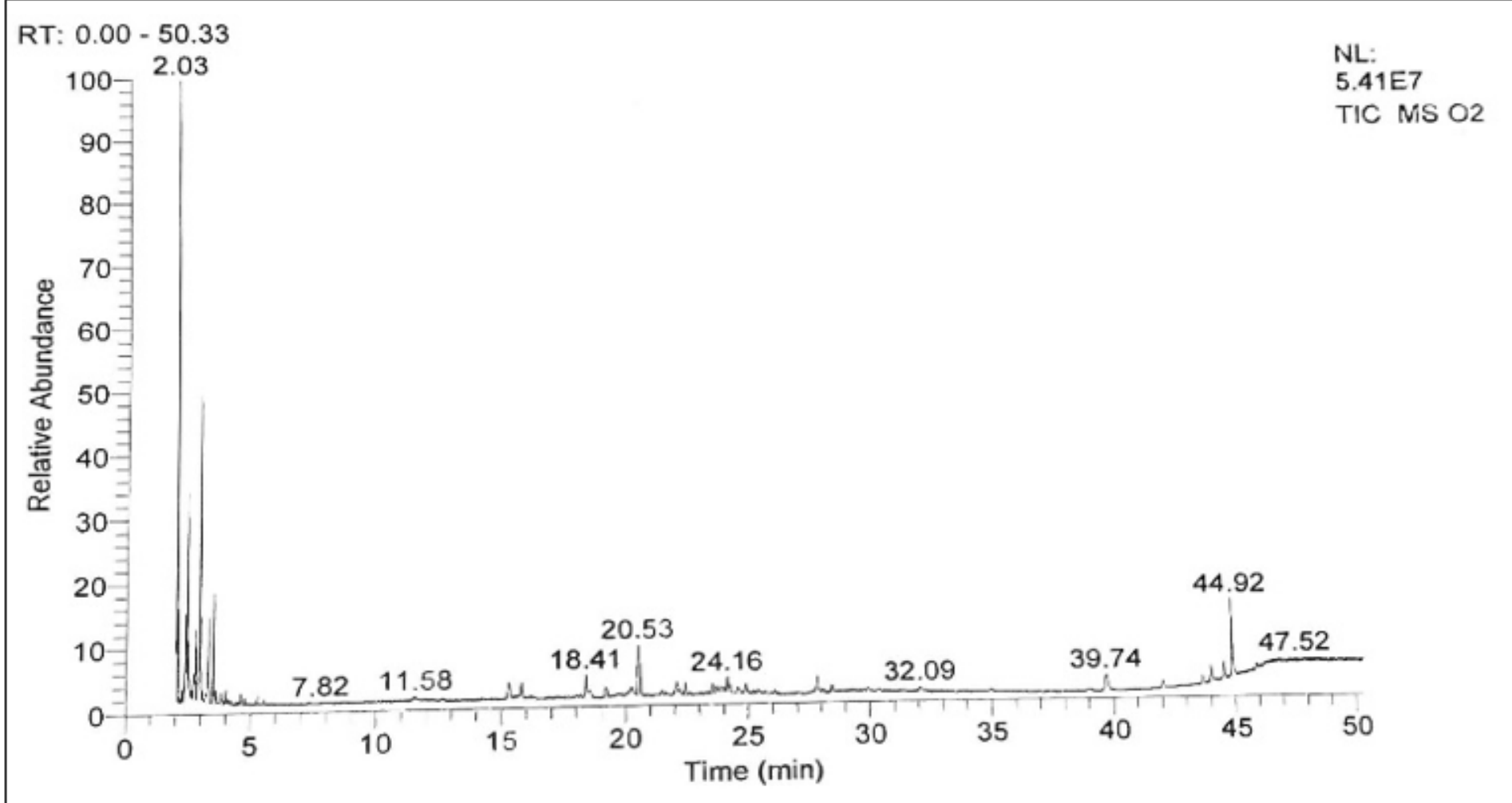

Figure 3 
Gas chromatography-mass spectrometry chromatogram of $U$. maritima calli methanolic extract. 